\title{
UV irradiation of pig metaphase chromosomes: maturation-promoting factor degradation, nuclear cytology and cell cycle progression
}

\author{
C. L. V. Leal ${ }^{1,2}$, C. Lee ${ }^{1}$ and R. M. Moor ${ }^{1 *}$ \\ ${ }^{1}$ Protein Function Laboratory, The Babraham Institute, Babraham, Cambridge, CB2 4AT, UK; and 'Department of Animal Reproduction, \\ Faculty of Veterinary Medicine and Animal Science, University of São Paulo, São Paulo, CEP 05580-900, Brazil
}

\begin{abstract}
Experiments were designed to test two hypotheses. The first was that irradiation of pig metaphase chromosomes would block the normal sequence of cytological and molecular events associated with activation; the second postulated that damaged DNA would prevent eggs from progressing through the first mitotic cleavage cycle. The experimental protocol involved selectively irradiating the metaphase II plate of pig oocytes with highly focused $254 \mathrm{~nm}$ ultraviolet (UV) light, followed by activation using standard electroactivation procedures. The following assessments were made of different groups of eggs: (i) nuclear membrane reassembly; (ii) chromosomal cytology; (iii) changes in maturation-promoting factor kinase (MPF kinase) activity at $1 \mathrm{~h}$ intervals after activation; and (iv) mitotic progression of eggs containing damaged chromosomal fragments. UV irradiation neither prevented the reassembly of nuclear membranes required for pronuclear formation nor interfered with the normal pattern of MPF kinase degradation after egg activation. UV irradiation did induce a wide range of chromatin defects, including condensation and dispersal of DNA fragments which, in turn, resulted in the formation of micronuclei in the treated eggs and embryos. The presence of damaged DNA retarded, but did not inhibit, progression through the first mitotic cycle. No evidence was obtained that the subsequent mitotic cycle was adversely affected by the presence of UV-damaged DNA. Overall, these results indicate that early cleavage divisions in pig eggs are not blocked by the presence of damaged, hypercondensed chromatin. In this respect, pig eggs are similar to Xenopus eggs, but are different from bovine eggs. On the basis of these findings it is suggested that focused UV irradiation offers a simple and rapid technique for the non-invasive enucleation of pig oocytes provided that the residual hypercondensed chromatin does not affect later developmental stages.
\end{abstract}

\section{Introduction}

Ultraviolet (UV) irradiation of the nucleus of oocytes provides a simple means of non-invasive enucleation for future cloning programmes provided that the presence of damaged maternal DNA in the resulting cytoplasts does not interfere with subsequent cell cycle progression. In testing this proposition in bovine oocytes, Bradshaw et al. (1995) demonstrated that accurately focused short wavelength UV light effectively destroyed chromosomal function without causing cytoplasmic damage as occurs after irradiation of the entire cell. However, after irradiation of the second metaphase plate in bovine oocytes, maturation-promoting factor (MPF) kinase degradation and pronuclear formation were compromised. The experiments in the present study are based on preliminary observations indicating that, in

*Correspondence.

Received 11 August 1998. contrast to bovine oocytes, pronuclear formation in pig oocytes is not compromised after UV irradiation. The objective of the present study was to extend these preliminary observations by determining the effect of short wavelength UV light on chromatin organization and cell cycle progression in pig oocytes. In addition to determining the UV sensitivity of pig oocytes, the experiments were also designed to contribute to the long-term aim of improving enucleation procedures in mammalian eggs.

After escape from the extended G2-phase block, mammalian oocytes progress to metaphase II, in which the meiotic cycle is subjected to a second period of arrest. Paradoxically, the presence of high concentrations of active cyclin-dependent kinase (referred to in oocytes as MPF kinase) is required both for escape from the first meiotic cycle block at the germinal vesicle (GV) stage and also for induction of the second period of arrest at metaphase II. Exit from metaphase II arrest and entry into the first mitotic cycle is initiated by a marked decrease in MPF kinase activity 
induced by sperm penetration, which in turn increases intracellular calcium and induces ubiquitin-mediated cyclin degradation (Glotzer et al., 1991). In a study of bovine oocytes, Bradshaw et al. (1995) showed that early events in the metaphase II to anaphase II transition are interrupted by irradiation. Although sperm penetration and decondensation occurred normally, the subsequent degradation of cyclin and the decrease in MPF kinase did not occur in bovine oocytes subjected to UV irradiation. The resulting inhibition of meiosis is paralleled in somatic cells in which UV irradiation also induces cell cycle arrest (Devary et al., 1992; Dhanwada et al., 1995). However, detailed studies on somatic cells revealed that irradiation-induced arrest occurs at a number of different points in the mitotic cell cycle (Terada et al., 1995). In general, these forms of mitotic cycle inhibition are closely associated with mechanisms of DNA repair (Carrier et al., 1994). The specific points of arrest are invariably correlated with well established mitotic checkpoints, the function of which is to delay or prevent either DNA replication or chromatid segregation in cells containing damaged DNA (see Hartwell and Weinert, 1989; Murray, 1993). It is during the period of enforced delay that the repair mechanisms within the nucleus operate to correct the DNA lesions or, failing that, to redirect the cell into an apoptotic pathway (Enoch and Norbury, 1995). There is evidence that the checkpoint control mechanisms in oocytes, and hence the response of these cells to DNA damage, may differ from those in somatic cells (Fulka et al., 1994). These differences probably reflect the unique nature of the meiotic cycle (see Bradshaw et al., 1995) and indicate that the response to UVinduced DNA damage may likewise be of a specialized nature in oocytes.

Differences in response to UV irradiation in oocytes is important not only from a cell cycle perspective but also for more practical reasons. The elimination of the chromosome complement of the oocytes is essential for nuclear transplantation. Although physical methods of enucleation are widely used at present, the results of Procháska and Fiser (1995) indicate that this approach adversely affects the ability of the resulting cytoplast to reprogramme the transplanted nucleus appropriately. Non-invasive enucleation systems have been suggested as a means of overcoming this problem, including the use of chemical agents (Fulka and Moor, 1993) and centrifugation (Tatham et al., 1995). UV irradiation has been suggested both as a method for the full functional enucleation of oocytes (Yang et al., 1990) and for the production of gynogenic oocytes by inactivating sperm DNA (Guo et al., 1993). Although focused UV irradiation effectively inactivates the DNA in bovine oocytes with minimal damage to the cytoplasm, its usefulness in that species is limited because of the concomitant arrest of cell cycle progression (Bradshaw et al., 1995).

The present study was conducted with three specific objectives in mind. The first was to determine whether focused UV irradiation inactivates DNA in pig oocytes without causing general damage to other cellular components. The second was to investigate the ability of irradiated pig oocytes to respond to activation stimuli by inhibiting MPF kinase activity, completing meiosis and supporting pronuclear formation. The third was to determine the ability of eggs to undergo mitosis and cleavage after irradiation of the metaphase II plate. The pig oocyte was studied not only because of its commercial importance, but also because it provides the closest convenient model to the human oocyte.

\section{Materials and Methods}

\section{Collection and culture of oocytes}

Pig ovaries were obtained from a local abattoir and transported to the laboratory in a thermocontainer at $24^{\circ} \mathrm{C}$. Oocytes were collected by aspiration of antral follicles (2-5 mm diameter) using a 16-gauge needle and syringe. Oocytes were cultured according to the method of Staigmiller and Moor (1984). Briefly, oocytes were washed twice in dissection medium (Hepes-buffered TCM 199; Sigma, St Louis, MO) and transferred to $35 \mathrm{~mm}$ Petri dishes containing $2 \mathrm{ml}$ maturation medium (bicarbonate-buffered TCM 199, Sigma) supplemented with $10 \%(\mathrm{v} / \mathrm{v})$ fetal calf serum (FCS; Gibco-BRL, Burlington, Ontario), $0.3 \mathrm{iu}$ $\mathrm{hFSH} \mathrm{ml}^{-1}$ and $0.3 \mathrm{hLH}^{\mathrm{hu} \mathrm{ml}} \mathrm{m}^{-1}$ (Pergonal, Serono, Rome). Two follicle shells prepared from 3-5 mm non-atretic follicles were added to each dish at the initiation of culture, which was thereafter carried out at $38.5^{\circ} \mathrm{C}$ in $5 \% \mathrm{CO}_{2}$ in humidified air (Mattioli et al., 1988). All oocytes were matured for $44 \mathrm{~h}$ and then the cumulus cells were removed. Oocytes that had extruded the first polar body were allocated randomly to either control or UV-irradiated groups. Oocytes allocated to the treated groups were irradiated at $44 \mathrm{~h}$; control and irradiated groups were cultured for a further $8 \mathrm{~h}$ (to $52 \mathrm{~h}$ ) before they were subjected to electrical activation. The culture of oocytes after electrical activation varied from 8 to $72 \mathrm{~h}$ (see Tables 1 and 2). Thereafter, eggs and embryos were prepared for morphological or chemical analysis.

\section{UV irradiation}

The irradiation protocols were as described Bradshaw et al. (1995). Briefly, denuded oocytes were incubated in Hepesbuffered TCM-199 with $10 \%$ (v/v) FCS, supplemented with $1 \mu \mathrm{g}$ bis-benzimide Hoechst stain $33342 \mathrm{ml}^{-1}$ (Calbiochem, La Jolla, CA) for $5 \mathrm{~min}$ at $38.5^{\circ} \mathrm{C}$ and were then washed four times in TCM-199. Groups of five to ten oocytes were placed in a drop of TCM-199 on a quartz coverslip held in a perspex chamber. A tight focus of the UV light source was obtained by using a $\times 32$ quartz objective (Ultrafluar, Zeiss Inc., Thornwood, NY) placed in a modified inverted epifluorescence microscope (T'MD Diaphot, Nikon, London). This was equipped with a $100 \mathrm{~W}$ mercury lamp (HBO 100 $W / 2$, Zeiss); all optical elements in the light path were constructed from quartz. A shutter held the following filters in parallel: (i) a total UV light cut-off and (ii) a UV-A filter (330-380 $\mathrm{nm}$ excitation). The third position in the shutter was left open for irradiation at $254 \mathrm{~nm}$ (UV-C). Individual oocytes were examined using the UV-A filter together with a $420 \mathrm{~nm}$ emission filter (UV-2A, Nikon) to identify the position of the Hoechst-stained chromosomes. The use of an adjustable 
Table 1. Number of control and ultraviolet-irradiated pig oocytes showing pronuclear development and chromatin defects $8 \mathrm{~h}$ after activation

\begin{tabular}{|c|c|c|c|c|c|c|}
\hline Treatment & \multicolumn{4}{|c|}{ Pronuclear formation } & \multicolumn{2}{|c|}{ Chromatin defects } \\
\hline Activated controls & 45 & $29^{a}$ & $3^{a}$ & $3^{a}$ & $2^{a}$ & $1^{\mathrm{a}}$ \\
\hline Irradiated and activated oocytes & 43 & $29^{a}$ & $18^{\mathrm{b}}$ & $2^{\mathrm{a}}$ & $12^{\mathrm{b}}$ & $11^{b}$ \\
\hline
\end{tabular}

abWithin columns, different letters indicate that means are significantly different $(P<0.05)$.

Table 2. Rate of pronuclear formation and cleavage in electroactivated control and UV-irradiated pig oocytes cultured for 24 , 48 or $72 \mathrm{~h}$ before examination

\begin{tabular}{|c|c|c|c|c|c|c|}
\hline Treatment & $\begin{array}{l}\text { Time from } \\
\text { activation to } \\
\text { fixation }(h)\end{array}$ & $\begin{array}{c}\text { Total } \\
\text { oocytes }\end{array}$ & $\begin{array}{c}\text { Number of } \\
\text { activated } \\
\text { oocytes }\end{array}$ & $\begin{array}{c}\text { One-cell } \\
(\%)\end{array}$ & $\begin{array}{c}\text { Two-cell } \\
(\%)\end{array}$ & $\begin{array}{l}\text { Three- to } \\
\text { four-cell } \\
(\%)\end{array}$ \\
\hline Irradiated & 24 & 46 & $29^{a}$ & $29(100)^{b}$ & $0^{\mathrm{b}}$ & $0^{\mathrm{a}}$ \\
\hline Control & 48 & 46 & $21^{\mathrm{a}}$ & $14(67)^{\mathrm{a}}$ & $3(14)^{\mathrm{a}}$ & $4(19)^{\mathrm{a}}$ \\
\hline Irradiated & 48 & 20 & $16^{\mathrm{a}}$ & $9(56)^{a}$ & $3(19)^{\mathrm{a}}$ & $4(25)^{a}$ \\
\hline
\end{tabular}

abWithin columns, different superscripts indicate that means are significantly different $(P<0.05)$.

Comparisons were made between control and irradiated oocytes for each period of culture $(24,48$ and $72 \mathrm{~h})$.

diaphragm enabled the field of exposure to be restricted to the metaphase plate. Once tight focus on the metaphase chromosomes was achieved, irradiation was performed for 0.5-1.0 s through the UV-C shutter. After irradiation, oocytes were cultured for $4 \mathrm{~h}$ (to $48 \mathrm{~h}$ ) before activation. It was not possible to measure accurately the precise dose of UV at the chromosomes because of the tight focus of the beam (see Bradshaw et al., 1995 for discussion on UV dose monitoring). However, the use of a UVX radiometer (UVP Ltd, Cambridge) equipped with a $254 \mathrm{~nm}$ short wavelength sensor and. careful standardization of all parameters (for example lamp, filters, quartz objectives and coverslips) enabled the conditions described by Bradshaw et al. (1995) to be replicated accurately in all the experiments. It is necessary to make a clear distinction between short wavelength UV light (254 nm) and the longer wavelength UV components of the spectrum, the effects of which on DNA are much more attenuated.

\section{Electrical activation}

Oocytes were equilibrated for $5 \mathrm{~min}$ in pulse medium (0.28 mmol inositol $\mathrm{l}^{-1}, 0.1 \mathrm{mmol} \mathrm{CaCl} \mathrm{m}^{-1}, 0.1 \mathrm{mmol} \mathrm{MgSO}_{4}$ $\mathrm{l}^{-1}, 10 \mathrm{mmol}$ histidine $\mathrm{l}^{-1}, \mathrm{pH} 7.0$ ) and were then submitted to three DC pulses of $1.0 \mathrm{kV} \mathrm{cm}$-1 field strength for $50 \mu$ s at 5 min intervals (Liu and Moor, 1995) using a BTX Electro Cell Manipulator 200 (BTX Inc., San Diego, CA). Oocytes were incubated for a further $8 \mathrm{~h}$ to $72 \mathrm{~h}$ before they were harvested for morphological or biochemical studies.

\section{Morphological analysis}

In the first experiment (see Table 1), both UV-irradiated and control oocytes were activated at $48 \mathrm{~h}$ and then cultured for a further $8 \mathrm{~h}$ before fixation to analyse pronuclear formation and chromatin cytology. In the second experiment (Table 2) irradiated and control oocytes were cultured for 24, 48 and $72 \mathrm{~h}$ after activation to assess rate of cleavage.

Oocytes were fixed for $1 \mathrm{~h}$ in a fixative solution of PBS (Oxoid), 4\% (w/v) paraformaldehyde and $3 \mu$ Triton-X100 $\mathrm{ml}^{-1}$, and washed three times in PPB (PBS with $1 \mathrm{mg}$ polyvinyl-alcohol (PVA) $\mathrm{ml}^{-1}$ and $1 \%(\mathrm{w} / \mathrm{v})$ BSA). Oocytes were treated with goat serum for $45 \mathrm{~min}$ and incubated overnight in anti-lamin A and $\mathrm{C}$ antibody (MRC Laboratory of Molecular Biology, Cambridge) at a 1:10 dilution in a humidified chamber at $4^{\circ} \mathrm{C}$. Primary antibody oocytes were washed three times for $15 \mathrm{~min}$ in PPB and incubated for $45 \mathrm{~min}$ in $2.5 \%(\mathrm{v} / \mathrm{v})$ fluorescein isothiocyanate (FITC)conjugated goat anti-IgG. Oocytes were then washed three times in PPB, stained with propidium iodide $\left(200 \mu \mathrm{g} \mathrm{ml}^{-1}\right)$ for $15 \mathrm{~min}$, washed three times in PPB, and mounted using antifade Vectashield mountant (Miyano et al., 1996). The slides were analysed using a laser scanning confocal microscope (MRC 600, Bio-Rad, Hemel Hempsted).

\section{Histone H1 kinase assay}

H1 kinase activity was assayed according to the method of Christmann et al. (1994), with minor modifications. Groups of three oocytes were placed in Eppendorf tubes containing 

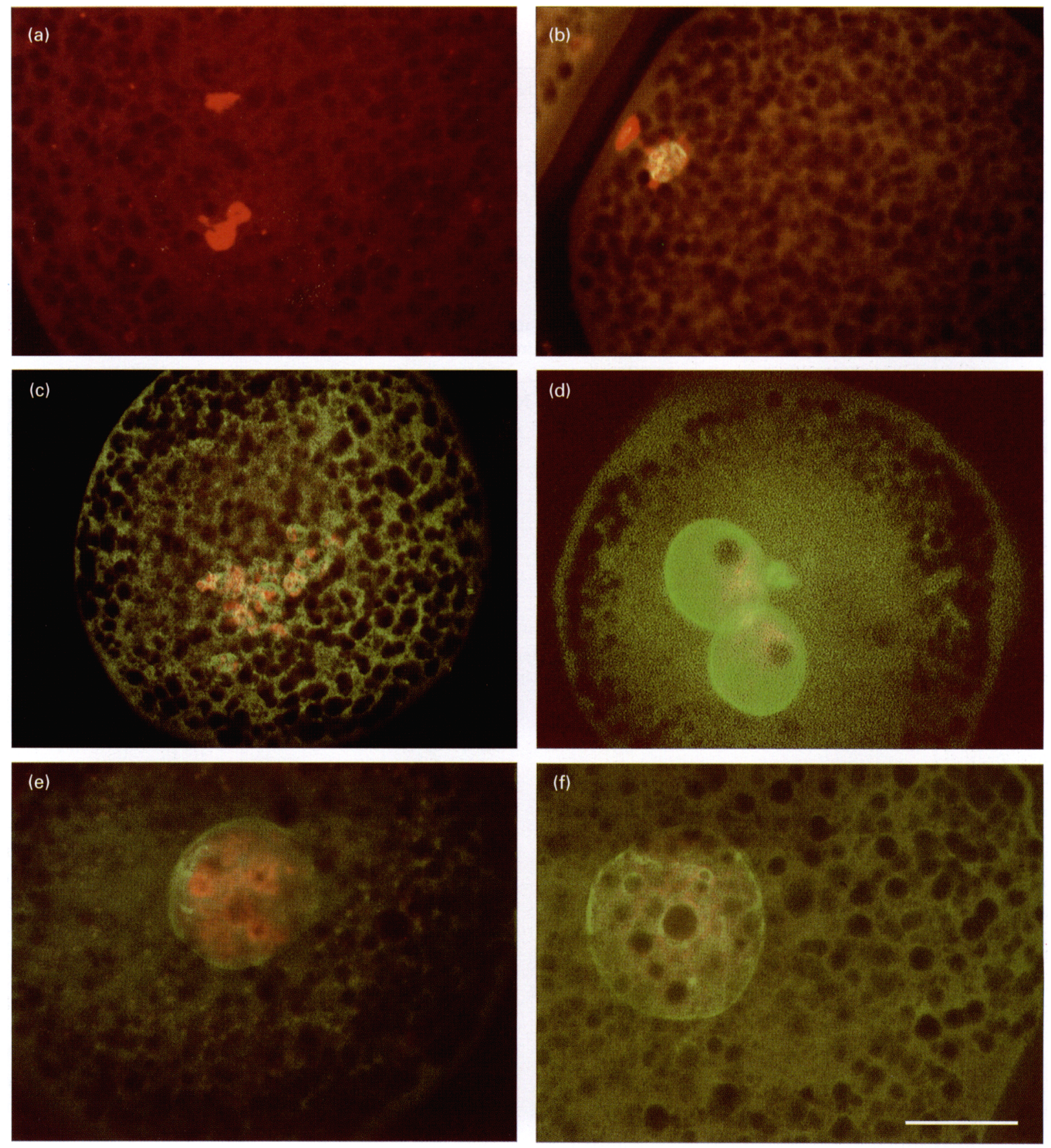

Fig. 1. Confocal photomicrographs of nuclear architecture in control pig oocytes and in oocytes subjected at $4 \mathrm{th}$ after the initiation of maturation to focused $254 \mathrm{~nm}$ ultraviolet irradiation. In the first experiment, oocytes were returned to culture for th after (a) irradiation or (b) sham treatment before fixation and staining with anti-tubulin antibody (green) and propidium iodide (red fluorescence). The hypercondensed metaphase chromatin in the irradiated oocyte (a) is in contrast to the normal metaphase II plate in the controls (b). Pronucleus configuration (c) and pronuclear chromatin organization (c) in oocytes irradiated at $44 \mathrm{~h}$, activated by electrostimulation at $48 \mathrm{~h}$, and fixed at $56 \mathrm{~h}$; corresponding pronuclei in sham irradiated oocyten are shown in (d) and $(t)$, respectively. The aberrant pronuclear structure and chromatin organization in irradiated eggs (c, $($ ) is in contrast to the normal pronuclei containing decondensed chromatin observed in sham irradiated eggs (d,f). l'ronuclear membranes were stained with fluorescein isothiocyanate (FITC)-labelled anti-lamin $A$ and C (green), while chromatin was stained with propidium iodide' (red). Scale bar represents $5 \mu m$.

3 il collection buffer $(6.4 \mathrm{mmol}$ EDTA 1 10 , 10 mol NaF 1 ' and $100 \mathrm{mmol} \mathrm{Na}_{3}, \mathrm{VO}_{4} \mathrm{l}^{-1}$ in PBS) and stored at $-70^{\circ} \mathrm{C}$ until used for the kinase assay. Samples were collected at 0 h (just before activation), $30 \mathrm{~min}, 1 \mathrm{~h}, 2 \mathrm{~h}, 3 \mathrm{~h}, 4 \mathrm{~h}$ and $8 \mathrm{~h}$ after activation. Non-irradiated but activated control oocytes were collected at the same intervals as the irradiated group. After thawing, $3 \mu l$ homogenization buffer (HB) $(45 \mathrm{mmol}$ b-glycerophosphate 1', 12 mmol p-nitrophenilphosphate l', $20 \mathrm{mmol} 3-(\mathrm{N}$-morpholino)-propanesulfonic acid I', pH 7.2, $12 \mathrm{mmol} \mathrm{MgCl}_{2} \mathrm{I}$, $12 \mathrm{mmol}$ ethileneglycol-bis (b-amino- 
ethylether) $N, N, N 1, N 1$-tetra-acetic acid $1^{-1}, 0.1$ mmol ethylenediamine tetra-acetic acid $\mathrm{l}^{-1}, 0.8 \mathrm{mmol}$ dithiothreitol (DTT) $\left.\mathrm{l}^{-1}\right)$ was added to the sample. After incubation at $37^{\circ} \mathrm{C}$ for $15 \mathrm{~min}, 4 \mu \mathrm{l}$ kinase buffer $(\mathrm{KB})$ was added $(45 \mathrm{mmol}$ b-glycerophosphate $\mathrm{l}^{-1}, 12 \mathrm{mmol} p$-nitrophenilphosphate $\mathrm{l}^{-1}$, $20 \mathrm{mmol} 3-\left(\mathrm{N}\right.$-morpholino)-propanesulfonic acid $\mathrm{l}^{-1}, \mathrm{pH} 7.2$, $12 \mathrm{mmol} \mathrm{MgCl}_{2} \mathrm{1}^{-1}, 12 \mathrm{mmol}$ ethileneglycol-bis (b-aminoethylether) $N, N, N 1, N 1$-tetra-acetic acid ${ }^{-1}, 0.1 \mathrm{mmol}$ ethylene-

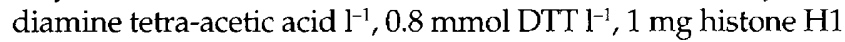
(type III-S from calf thymus) $\mathrm{ml}^{-1}, 2.2 \mu \mathrm{mol}$ protein kinase inhibitor peptide (TTYADFIASGRTGRRNAIHD ${ }^{-1}$ ) and 1.8 $\mathrm{MBq} \mathrm{ml}$ [gamma- ${ }^{32} \mathrm{P}$ ] ATP $\left.\mathrm{I}^{-1}\left(166 \mathrm{TBq} \mathrm{mmol} \mathrm{I}^{-1}\right)\right)$. The reaction was allowed to proceed for $30 \mathrm{~min}$ at $37^{\circ} \mathrm{C}$ and was then terminated by the addition of $10 \mu \mathrm{l} 2 \times$ SDS sample buffer (Laemmli, 1970) to a final volume of $20 \mu 1$. The sample was boiled for $5 \mathrm{~min}$ at $90^{\circ} \mathrm{C}$ and then loaded on to a $10 \%(\mathrm{w} / \mathrm{v})$ polyacrylamide gel for one-dimensional SDS electrophoresis for the separation of the radiolabelled histone $\mathrm{H} 1$. After electrophoresis, the gel was dried and the kinase activity was quantitated by direct analysis of radioactivity of the gels using a GS-525 Molecular Imager System (Bio-Rad, Hemel Hempsted). The activity was measured for each sample and an average measure from the experiments was determined. Oocytes at $48 \mathrm{~h}$ were arbitrarily designated to represent $100 \%$ activity (this stage showed the highest activity); the activities of oocytes at the other stages are presented as a proportion of this activity.

\section{Statistical analysis}

The statistical significance of the rate of pronuclear formation, abnormal pronuclear formation, chromatin defects and cleavage was evaluated by the chi-squared test. For H1 kinase activity, analysis of variance was performed using a randomized design with a scheme of parcels subdivided in time, considering the groups as parcels (controls and UV-irradiated oocytes) and time after activation as subparcels $(0,0.5,1,2,3,4$ and $8 \mathrm{~h})$. The data, in percentage, were corrected by the arcsine transformation of the square root of the percentage, and means were compared by Tukey's test. Analysis was carried out using the GLM (general linear model) procedure of the Statistical Analysis System (SAS) software, with a significance level of $5 \%$.

\section{Results}

\section{Effects of irradiation on metaphase II plate organization}

In the first series of experiments, oocytes were cultured to metaphase II, subjected after polar body extrusion to focused $254 \mathrm{~nm}$ UV irradiation, returned to culture for $4 \mathrm{~h}$ and fixed for chromosomal analysis. The experiments were carried out on 80 oocytes, 41 of which were UV irradiated and the remainder were controls. Within $4 \mathrm{~h}$, in 20 of 41 irradiated oocytes, the chromatin had undergone clumping and hypercondensation (Fig. 1a). In contrast, metaphase plate organization remained intact over the same period in all the control non-irradiated oocytes (Fig. 1b). After demonstrating that $254 \mathrm{~nm}$ UV irradiation induces rapid hypercondensation and chromatin clumping in a similar manner to that in bovine oocytes (Bradshaw et al., 1995), the second series of experiments was designed to test the hypothesis that UV irradiation at metaphase II would prevent, or significantly delay, the formation of female pronuclei in pig oocytes. In these experiments, irradiated and control oocytes were cultured for $8 \mathrm{~h}$ after electrical activation before the oocytes were fixed and stained with lamin antibody and propidium iodide to visualize nuclear membrane formation and chromatin organization, respectively. In addition, the pattern of MPF kinase degradation after activation of control and UV-irradiated oocytes was also assessed.

\section{Effects of irradiation on pronuclear formation}

Egg activation. The percentage of irradiated and nonirradiated control eggs showing pronuclear development and chromatin defects is presented (Table 1). Activation, as assessed by pronuclear formation, occurred in 29 of $45(64.4 \%)$ of electrically stimulated control oocytes. A comparable percentage of pronucleate eggs $(67.4 \%)$ was observed in oocytes irradiated at metaphase II and activated thereafter.

Pronuclear organization. Although pronuclei formed in almost $70 \%$ of irradiated eggs, they differed from the controls in a number of important respects. Firstly, a significantly higher proportion $(P<0.05)$ of pronuclei in irradiated oocytes showed structural abnormalities (18 of $29,62 \%$ ) compared with controls ( 3 of 29, 10\%). These gross abnormalities were characterized by the formation of multiple pronuclei of different sizes (see Fig. 1c). In contrast, in controls, two pronuclei arising from failure of second polar body extrusion were observed in less than $10 \%$ of eggs (Fig. 1d). In addition to the effects on gross pronuclear structure outlined earlier, defects were also observed in the chromatin component within the pronuclei (Table 1). In the irradiated group of pronucleate eggs, almost 40\% (11/29) displayed chromatin defects, which included hypercondensation, DNA strand breaks and chromosome dispersal (see Fig. 1c,e). In contrast, almost no chromatin abnormalities (Fig. 1f) were observed in the pronuclei of non-irradiated oocytes $(1 / 29)$.

Non-activated oocytes. Hypercondensation and other chromosome defects were observed in virtually all $(86 \%)$ of the irradiated oocytes that failed to respond to the activation stimulus (Table 1). These results are in marked contrast to the control oocytes that failed to activate, in which only $12 \%$ showed chromosomal defects.

\section{MPF kinase activity}

The effect on MPF kinase activity of activating irradiated or control oocytes was assayed using histone H1 kinase as substrate. In non-irradiated control oocytes, MPF kinase activity decreased sharply after activation; $60 \%$ of kinase 


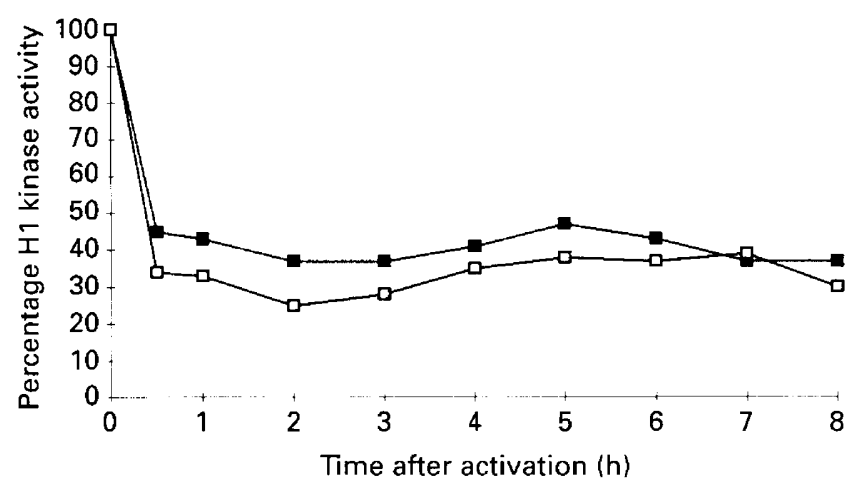

Fig 2. Relative changes in histone H1 kinase activity of $(\square)$ irradiated and $(\square)$ non-irradiated pig oocytes after activation. In each of three replicate experiments, the H1-kinase activity was measured in oocytes before activation $(0 \mathrm{~h})$ and at intervals after activation $(1-8 \mathrm{~h})$. Within each replicate, the measured activity was expressed as a percentage of that in the non-activated metaphase II group $(0 \mathrm{~h})$. The overall mean percentage change in 18 oocytes at each time point is shown.

activity was lost within the first $30 \mathrm{~min}$ after electrostimulation. The rate of histone $\mathrm{H} 1$ kinase inactivation in irradiated oocytes was similar to that in the controls; there was a rapid initial loss after electrostimulation of approximately $70 \%$ of peak metaphase II values in the first $30 \mathrm{~min}$. Basal MPF kinase activity persisted for the ensuing $8 \mathrm{~h}$ in both groups of oocytes (Fig. 2).

As expected from the $\mathrm{H} 1$ kinase data presented above, B-type cyclin degradation and hyperphosphorylation of the p34 ${ }^{\text {cdc }}$ catalytic subunit were observed after activation in both irradiated and control pig oocytes (data not shown).

\section{Early mitotic progression}

The final series of experiments tested the hypothesis that mitotic cleavage is blocked by the presence of damaged DNA. The results indicate that the effects of irradiation may be to retard rather than to block mitosis (Table 2). A total of $41 \%$ of control parthenogenetic eggs had undergone cleavage to the two-cell stage at $24 \mathrm{~h}$ after activation. Although there was some progression to the four-cell stage in control groups cultured for 48 or $72 \mathrm{~h}$, the total number of cleaved eggs remained relatively constant at about $40 \%$. In contrast, cleavage had not occurred in the irradiated oocytes at $24 \mathrm{~h}$ after activation. Irradiated groups examined at 48 or $72 \mathrm{~h}$ after activation were similar to controls: approximately $40 \%$ had undergone cleavage, indicating that the delay at $24 \mathrm{~h}$ was transient. The morphology of cleaved irradiated oocytes was interesting, as in addition to nucleated blastomeres, a number of micronuclei were also often observed in these eggs (Fig. 3).

\section{Discussion}

The results of this study provide information on the effect of focused nuclear irradiation on meiotic progression in pig oocytes. Firstly, the results indicate that short wavelength $(254 \mathrm{~nm})$ UV light seriously damages the chromosome complement. Secondly, destruction of the DNA by focused irradiation appears to occur with minimal damage to stored mRNA, mitochondrial DNA and cytoplasmic activity, as evidenced by subsequent normal synthesis of cell cycle molecules and mitotic progression. Thirdly, UV-damaged DNA in pig oocytes does not activate checkpoint-induced arrest in the transition between metaphase II and anaphase II. Activation induces MPF-kinase destruction, exit from metaphase II and pronuclear formation. Thus a comparison of histone $\mathrm{H} 1$ kinase activity in irradiated and control metaphase II oocytes before and after activation shows that the kinetics of inactivation of this enzyme are similar in both groups of oocytes, despite severely damaged chromatin characterized by the dispersal of hypercondensed DNA fragments in the cytoplasm. Finally, the presence of chromosome fragments delays, but does not block, progression of mitosis and cleavage.

Scattered fragments or clumps of DNA were frequently observed as membrane-bound micronuclei in irradiated pig eggs from the pronuclear to the four-cell stage. Similar chromatin clumping was reported in irradiated bovine oocytes (Bradshaw et al., 1995). However, the presence of DNA fragments appears to be correlated with time in culture and would not therefore have been apparent in the study on bovine eggs, which was terminated at $16 \mathrm{~h}$ after egg activation. Although the formation of pyrimidine dimers between adjacent bases on the same DNA chain is the primary response to UV irradiation, strand breaks may occur during nucleotide excision repair. DNA repair in metaphase II oocytes is extremely limited (Masui and Pedersen, 1975), but increases substantially during mitosis. It is postulated that the appearance of DNA fragments reflects an increase in strand breaks during increased repair activity in early mitosis.

The use of lamin antibody as one of the probes has enabled comparison of the function of inner nuclear membrane proteins (Peter et al., 1990) in irradiated and control oocytes. It is concluded that proteins associated with nuclear membrane formation are not adversely affected by irradiation and that after activation nuclear membranes are formed rapidly in both treated and control oocytes. It is also clear from the results of this study that the rate at which nuclear membranes form around chromatin is not affected by the state of the DNA; membranes form rapidly around normal, hypercondensed and fragmented chromatin after activation.

In both the present study and that of Kim et al. (1996a), a small number of control oocytes $(10 \%)$ contained two pronuclei of equal size after activation. In contrast, a significantly increased number of irradiated oocytes contained multiple pronuclei of different size. There are at least two explanations that may account for this observation. Firstly, although the damage to the cytoplasm by focused irradiation appears to be very small, it is possible that there is localized damage to the spindle structure (see Kim et al., 1996b for description of pig oocyte spindle). UV damage to microtubules was reported by Zamansky et al. (1991). However, the finding that MPF kinase degradation is unaffected by irradiation and occurs in a similar manner in control oocytes after activation (Kikuchi et al., 1995) does not support this proposal. This is important since, in a variety of 

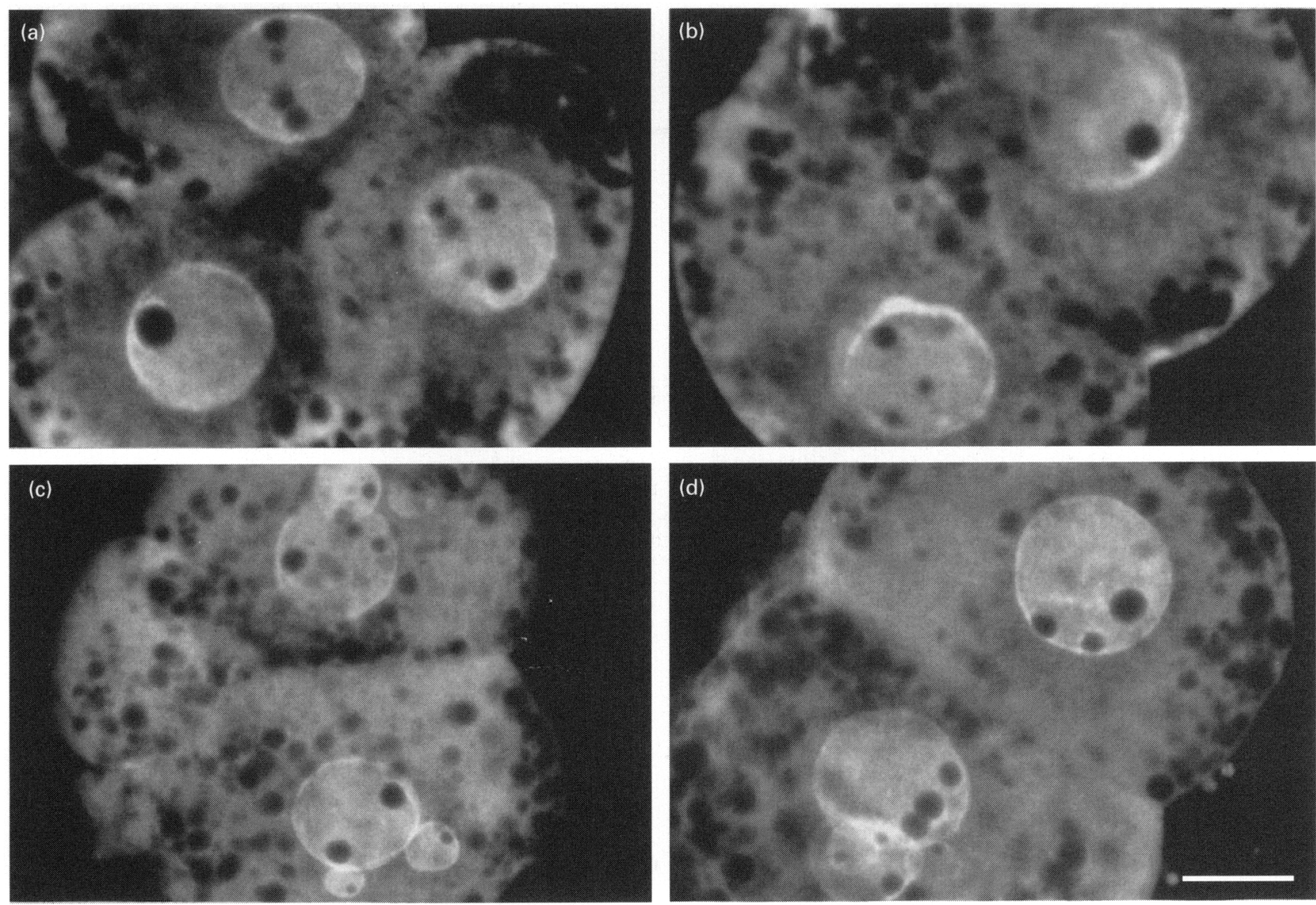

Fig. 3. Confocal photomicrographs of cleavage of parthenogenic embryos activated by electrostimulation. (a,b) Control non-irradiated embryos; nuclei in each blastomere are uniform in size. (c,d) Embryos derived from oocytes irradiated 4 h before activation contain nuclei of different sizes at the two-cell and the three- to four-cell stages. Embryos were stained with fluorescein isothiocyanate (FITC)-labelled anti-lamin $A$ and $C$ to highlight nuclear membranes. Scale bar represents $5 \mu \mathrm{m}$.

cells including eggs (Kubiak et al., 1993), unimpeded cyclin proteolysis, and consequent MPF kinase degradation (as observed in this study) occurs only in the presence of an undamaged spindle. A second explanation for the formation of multiple pronuclei in treated eggs is that UV-induced chromosomal fragments become dislodged from the spindle during anaphase and subsequently provide the stimulus for nuclear membrane reassembly and pseudo-pronuclear formation.

The results of this study indicate that MPF kinase degradation after activation in pig oocytes is unaffected by irradiation. This finding is in marked contrast to the study of Bradshaw it al. (1995) in which bovine oocytes were irradiated at metaphase II using the same equipment and conditions used in the present study. Exposure of bovine oocytes to $254 \mathrm{~nm}$ UV irradiation completely blocked MPF kinase degradation after ethanol-induced activation and prevented female pronuclear formation in the majority of eggs. After fertilization of metaphase II-irradiated bovine eggs, female pronuclear formation was prevented while male pronuclear formation was only slightly reduced compared with controls $(53 \%$ versus $72 \%)$. Since female pronuclear development occurred in irradiated pig oocytes, it is predicted that male pronuclear development would also occur. The difference in both biochemical and cytological responses to focused UV irradiation in bovine and pig oocytes can be explained by differences in UV sensitivity between the two species. However, the two experiments also differed in that method of activation used (ethanol versus electrical) and this may have influenced development after activation in the two species.

Although oocytes were able to form pronuclei and undergo cleavage to the four-cell stage, there was a delay in the first cell cycle of oocytes subjected to irradiation at metaphase II. The delay is probably due to the irradiation, since exposure to UV leads to unscheduled DNA synthesis in mouse oocytes (Masui and Pedersen, 1975) and to temporary arrest of the cell cycle in many somatic cells to allow repair of the damaged DNA (Hartwell and Weinert, 1989; Herzinger et al., 1995). Although growing oocytes have the ability to repair DNA damage (Ashwood-Smith and Edwards, 1996), this function is reduced or absent during maturation (Masui and Pedersen, 1975). Even though focused UV irradiation causes severe damage to genomic DNA it is probable that most mitochondrial DNA and stored mRNA escapes damage. This conclusion is based on the fact that similar 
numbers of irradiated and control pig eggs underwent cleavage to the four-cell stage in the present study. Furthermore, pig eggs are entirely dependent upon stored maternal mRNA for support during this period (Jarrell et al., 1991). In the present study, cleavage of parthenotes did not proceed beyond the four-cell stage in both groups, probably due to both the activation procedure and the culture conditions, which can affect parthenogenetic activation rates (Hagen et al., 1991; Funahashi et al., 1994; Chian and Sirard, 1995). Until normal young are produced, the possibility that irradiation and the presence of damaged DNA has some adverse effects on cleavage at later stages of development cannot be ruled out. Indeed, Guo et al. (1993) reported that the introduction of damaged DNA into Pacific oyster oocytes led to lower rates of development. Similarly, in a study on rabbit eggs, Yang et al. (1990) observed that cytoplasts prepared by whole cell irradiation underwent cleavage at normal rates to the four-cell stage, but were retarded thereafter.

Full irradiation of somatic cells has a number of effects such as activation of transcription factors, Src tyrosine kinases, calcium signalling pathways, RNA-binding proteins and MAP kinase signalling pathways (Devary et al., 1992; Schieven et al., 1993; Carrier et al., 1994; Dhanwada et al., 1995), which can affect subsequent cell function in several ways. However, in an extensive series of pioneering experiments on nuclear transplantation in Xenopus, Gurdon (1986) used UV irradiation for cytoplast enucleation. Despite the presence of damaged DNA, subsequent development of reconstructed eggs into fully viable young frogs was not compromised. The present results show that UV-irradiated pig oocytes degrade MPF kinase and form pronuclei in a manner that is indistinguishable from controls. However, it is clear that further experiments are required to determine whether pig cytoplasts produced from UV treatment are fully capable of supporting development to term.

C. L. V. Leal was supported by a scholarship granted by CNPqBrazil, ref. number 200950/94-0, and FAPESP-Brazil, ref. number 93/4323-3. The authors thank Dianne Styles and Karen Waterton for editorial assistance. Anti-lamin A and $\mathrm{C}$ antibody was generously donated by Murray Stewart, MRC Laboratory of Molecular Biology, Cambridge, UK.

\section{References}

Ashwood-Smith MJ and Edwards RG (1996) DNA repair by oocytes Molecular Human Reproduction $246-51$

Bradshaw J, Jung T, Fulka J, Jr and Moor RM (1995) UV irradiation of chromosomal DNA and its effect upon MPF and meiosis in mammalian oocytes Molecular Reproduction Development 41 503-512

Carrier F, Gatignol A, Hollander MC, Jeang KT and Fornace AJ, Jr (1994) Induction of RNA-binding proteins in mammalian cells by DNA-damaging agents Proceedings National Academy of Sciences USA 91 1554-1558

Chian RC and Sirard MA (1995) Effects of cumulus cells and folliclestimulating hormone during in vitro maturation or parthenogenetic activation of bovine oocytes Molecular Reproduction Development 42 425-431

Christmann L, Jung T and Moor RM (1994) MPF components and meiotic competence in growing pig oocytes Molecular Reproduction Development 38 $85-90$

Devary Y, Gottlieb RA, Smeal T and Karin M (1992) The mammalian ultraviolet response is triggered by activation of Src tyrosine kinases Cell $\mathbf{7 1}$ $1081-1091$
Dhanwada KR, Dickens M, Neads R, Davis R and Pelling JC (1995) Differential effects of UV-B and UV-C components of solar radiation on MAP kinase signal transduction pathways in epidermal keratinocytes Oncogene 11 1947-1953

Enoch T and Norbury C (1995) Cellular responses to DNA damage: cell cycle checkpoints, apoptosis and the roles of p53 and ATM Trends in Biochemistry $20426-430$

Fulka J, Jr and Moor RM (1993) Non-invasive chemical enucleation of mouse oocytes Molecular Reproduction Development 34 427-430

Fulka J, Jr, Bradshaw JP and Moor RM (1994) Meiotic cycle checkpoints in mammalian oocytes Zygote 2351-354

Funahashi H, Cantley TC, Stumpf TT, Terlouw SL and Day BN (1994) In vitro development of in vitro-matured porcine oocytes following chemical activation or in vitro fertilization Biology of Reproduction 50 1072-1077

Glotzer M, Murray AW and Kirschner MW (1991) Cyclin is degaded by the ubiquitin pathway Nature 349 132-138

Guo X, Hershberger WK, Cooper K and Chew KK (1993) Artificial gynogenensis with ultraviolet light-irradiated sperm in the Pacific oyster, Crassostrea gigas. I. Induction and survival Aquaculture 113 201-214

Gurdon J (1986) Nuclear transplantation in eggs and oocytes fournal of Cell Science Supplement 4 287-318

Hagen DR, Prather RS and First NL (1991) Response of porcine oocytes to electrical and chemical activation during maturation in vitro. Molecular Reproduction Development 28 70-73

Hartwell LH and Weinert TA (1989) Checkpoints: controls that ensure the order of the cell cycle events Science 246 629-634

Herzinger T, Funk JO, Hillmer K, Eick D, Wolf DA and Kind P (1995) Ultraviolet $B$ irradiation-induced G2 cell cycle arrest in human keratinocytes by inhibitory phosphorylation of the cdc2 cell cycle kinase Oncogene 11 2151-2156

Jarrell VL, Day BN and Prather RS (1991) The transition from maternal to zygotic control of development occurs during the 4-cell stage in the domestic pig, Sus scrofa: quantitative and qualitative aspects of protein synthesis Biology of Reproduction 44 62-68

Kikuchi K, Izaiki Y, Noguchi J, Furukawa T, Daen FP, Naito K and Toyoda Y (1995) Decrease of histone $\mathrm{H} 1$ kinase activity in relation to parthenogenetic activation of pig follicular oocytes matured and aged in vitro. Journal of Reproduction and Fertility 105 325-330

Kim NH, Moon SJ, Prather RS and Day BN (1996a) Cytoskeletal alteration in aged porcine oocytes and parthenogenesis Molecular Reproduction Development 43 513-518

Kim NH, Funahashi H, Prather RS, Schatten G and Day BN (1996b) Microtubule and microfilament dynamics in porcine oocytes during meiotic maturation Molecular Reproduction Development 43 248-255

Kubiak JZ, Weber M, Depennart H, Winston NJ and Maro B (1993) The metaphase-II arrest in mouse oocytes is controlled through microtubuledependent destruction of cyclin-B in the presence of CSF EMBO Journal 12 3773-3778

Laemmli UK (1970) Cleavage of structural proteins during assembly of the head of the bacteriophage T4 Nature 227 680-685

Liu L and Moor RM (1995) Optimisation of electrical activation of porcine oocyte matured in vitro. Journal of Reproduction and Fertility Abstract Series 15 Abstract 70

Masui Y and Pedersen RA (1975) Ultraviolet light-induced unscheduled DNA synthesis in the mouse oocytes during meiotic maturation Nature 257 705-706

Mattioli M, Galeati G and Seren E (1988) Effect of follicle somatic cells during pig oocyte maturation on egg penetrability and male pronuclear formation Gamete Research $20177-183$

Miyano T, Moor RM, Wooding FBP and Shiroo M (1996) Localization and function of tyrosine phosphorylated protein in pig oocytes Molecular Reproduction Development 44 408-416

Murray AW (1993) Turning on mitosis Current Biology 3 291-293

Peter M, Nakagawa J, Doree M, Labbe JC and Nigg EA (1990) In vitro disassembly of the nuclear lamina and $\mathrm{M}$-phase specific phosphorylation of lamins by cdc 2 kinase Cell 61 591-602

Procháska R and Fiser PS (1995) Behaviour of blastomere nuclei fused to mouse oocytes is affected by oocyte enucleation and age Reproduction Nutrition Development 35 695-701

Schieven GL, Kirihara JM, Gilliland LK, Uckun FM and Ledbetter JA (1993) Ultraviolet radiation rapidly induces tyrosine phosphorylation and calcium signalling in lymphocytes Molecular Biology of the Cell 4 523-530

Staigmiller RB and Moor RM (1984) Effect of follicle cells on the maturation 
and developmental competence of ovine oocytes matured outside the follicle Gamete Research $9221-229$

Tatham BG, Dowsing AT and Trounson AO (1995) Enucleation by centrifugation of in vitro matured bovine oocytes for use in nuclear transfer Biology of Reproduction 53 1088-1094

Terada Y, Tatsuka M, Jinno S and Okayama H (1995) Requirements for tyrosine phosphorylation of Cdk4 in G1 arrest induced by ultraviolet irradiation Nature 376 358-362
Yang X, Zhang L, Kovács A, Tobback C and Foote RH (1990) Potential of hypertonic medium treatment for embryo micromanipulation II. Assessment of nuclear transplantation methodology, isolation, subzona insertion, and electrofusion of blastomeres of intact or functionally enucleated oocytes in rabbits Molecular Reproduction Development 27 118-129

Zamansky GB, Perrino BA and Chou IN (1991) Disruption of cytoplasmic microtubules by ultraviolet radiation Experimental Cell Research 195 269-273 